\title{
Identification of flap motion parameters for vibration reduction in helicopter rotors with multiple active trailing edge flaps
}

\author{
Uğur Dalli ${ }^{\mathrm{a}, *}$ and Şefaatdin Yüksel ${ }^{\mathrm{b}}$ \\ ${ }^{a}$ ASELSAN Inc., MGEO Division, 06511 Akyurt, Ankara, Turkey \\ ${ }^{\mathrm{b}}$ Department of Mechanical Engineering, Faculty of Engineering and Architecture, Gazi University, 06570 \\ Maltepe, Ankara, Turkey
}

Received 1 October 2009

Revised 21 April 2010

\begin{abstract}
An active control method utilizing the multiple trailing edge flap configuration for rotorcraft vibration suppression and blade loads control is presented. A comprehensive model for rotor blade with active trailing edge flaps is used to calculate the vibration characteristics, natural frequencies and mode shapes of any complex composite helicopter rotor blade. A computer program is developed to calculate the system response, rotor blade root forces and moments under aerodynamic forcing conditions. Rotor blade system response is calculated using the proposed solution method and the developed program depending on any structural and aerodynamic properties of rotor blades, structural properties of trailing edge flaps and properties of trailing edge flap actuator inputs. Rotor blade loads are determined first on a nominal rotor blade without multiple active trailing edge flaps and then the effects of the active flap motions on the existing rotor blade loads are investigated. Multiple active trailing edge flaps are controlled by using open loop controllers to identify the effects of the actuator signal output properties such as frequency, amplitude and phase on the system response. Effects of using multiple trailing edge flaps on controlling rotor blade vibrations are investigated and some design criteria are determined for the design of trailing edge flap controller that will provide actuator signal outputs to minimize the rotor blade root loads. It is calculated that using the developed active trailing edge rotor blade model, helicopter rotor blade vibrations can be reduced up to $36 \%$ of the nominal rotor blade vibrations.
\end{abstract}

\section{Introduction}

Helicopters are subject to high levels of vibrations due to flexible rotor blades operating in a complex unsteady aerodynamic environment. The periodic inertial and aerodynamic loads on the rotor blades are transmitted to the rotor hub and they are transferred throughout the helicopter structure. High vibration can cause significant crew and passenger discomfort, fatigue in rotor system components, increased maintenance requirements, increased likelihood of damage to critical avionics components and reduced performance of sensitive equipment.

Over the past several decades, there has been considerable effort to examine passive and active control strategies for helicopter vibration reduction. Passive approaches, such as pendulum absorbers, anti-resonance systems and other vibration absorbers or addition of mass to tune blades are often used to suppress vibration levels at some selected places in the helicopter body. Main drawbacks of passive devices are their large weight penalty and rapid performance degradation away from the tuned flight condition [1].

${ }^{*}$ Corresponding author: Dr. Uğur Dalli, ASELSAN Inc. MGEO Division, 06511 Akyurt, Ankara, Turkey. Fax: +90 312847 5320; E-mail: udalli@mgeo.aselsan.com.tr. 
Active control solutions are currently being investigated to suppress helicopter rotor vibration. The active approaches such as Higher Harmonic blade pitch Control (HHC) and Individual Blade Control (IBC) promise vibration suppression in a broadband of frequencies unlike passive techniques that are typically capable of suppressing vibration over a narrow frequency range [2,3]. In HHC, vibration is suppressed at the source through excitation of the blade pitch at higher harmonics of the rotational speed. IBC places actuators on the blade to control each blade independently and simultaneously to suppress the vibration at the source. These active methods can be very effective and have the ability to adapt to changes in operating condition, but they often have large power requirement, produce large pitch link loads, and involve considerable complexity [4].

A more direct approach for vibration reduction is to design the rotor for low vibration by tailoring structural, inertial and aerodynamic properties of the rotor blade. The rotor blade design process requires accounting for several disciplines such as aerodynamics, dynamics, structures, and acoustics simultaneously due to couplings and interactions between them. Integration of large computer programs is needed for analysis and for application of optimization techniques to the rotor blade design process.

Smart-materials induced-strain actuation for aeroelastic and vibration control has evolved from laboratory scale proof-of-concept demonstrations to full-scale helicopter implementation [5-8]. In the recent years, there has been growing interest in the use of trailing edge flaps on the main rotor blades to minimize the vibrations actively. The emergence of high energy density smart material actuators provides compact, mechanically simple, lightweight, low-actuation-power, and high-bandwidth control devices that can be used on trailing edge flaps for vibration suppression.

The performance of trailing-edge flaps for active control of vibration in rotorcrafts has been examined by a fairly extensive rotorcraft analyses and numerical simulations. Millott and Friedmann [9] studied servo flaps using a flexible blade model. In this study, the servo-flap design, where auxiliary airfoil sections are located aft of the trailing edge of the main blades were shown to be effective as conventional multicyclic pitch control but with greatly reduced power requirements. Lemnios and Wei et al. [10-12] presented modeling for the servo-flap utilized on Kaman's $\mathrm{SH}-2$ rotor.

Alternative to servo-flaps, plain trailing edge flaps have been chosen in most of the recently developed actively controlled rotors $[13,14]$. Plain trailing edge flap is integrated into the rotor blade by locating the flap actuation and support structure, hinge, and linkage assembly within the blade profile which results in a reduction in aerodynamic drag, and an increase of flap effectiveness by narrowing the hinge gap. Ormiston [15], using a simple rigid rotor model, explored the feasibility of a swashplateless rotor with plain trailing-edge flaps. Myrtle and Friedmann [16] presented a rotor code for the active flap using an unsteady aerodynamic model for airfoil/flap based on a rational function approximation approach. Milgram and Chopra $[17,18]$ study indicates the feasibility of a $10 \%$ span, $20 \%$ chord trailing-edge flap, with \pm 5 deg flap travel, in reducing vibratory hub loads. Koratkar and Chopra [19] developed and tested a Froude-scaled smart rotor having uniform piezoelectric bender to drive a $4 \%$ span, $20 \%$ chord flap located at 95\% span-wise location. Koratkar and Chopra [20] also tested a 4-bladed Mach-scaled rotor model in wind tunnel using Bell-412 hub in both open- and closed-loop studies. Fulton and Ormiston [21] have conducted wind tunnel tests on a model rotor with piezoelectric bender actuation and demonstrated the effectiveness of trailing edge flaps for reducing the harmonic blade vibratory flap bending moments. Shen and Chopra developed a comprehensive analysis [22] for a swashplateless rotor with trailing-edge flaps and showed that the plain flaps are capable of performing both primary rotor control and active vibration control functions. They also examined the key design parameters such as pitch index angle, flap location, flap length and chord ratio in the design of swashplateless and teetering rotors with plain trailing edge flaps [23,24].

The concept of on-blade active trailing edge flaps was investigated experimentally in the Active Blade Concept research program conducted by ONERA, DLR, Eurocopter France and Deutschland [6,25,26]. Wind tunnel tests performed on a Mach-scaled rotor with trailing edge flaps located outboard, from $69 \%$ to $90 \%$ of the blade radius and actuated by elliptical piezoelectric actuators proved to be successful as a $15 \%$ in reducing vibratory hub loads.

A variety of studies have examined the performance of trailing-edge flaps for active vibration control in rotorcraft. The review on this topic shows that most of research has been restricted to the use of single trailing edge flaps. Therefore, there is a need to analyze the use of multiple active trailing edge flaps on rotor blades. The objective of the present study is to evaluate the performance of multiple plain trailing edge flap system for rotorcraft vibration suppression and blade loads control. The study included active open loop control method utilizing the multiple 


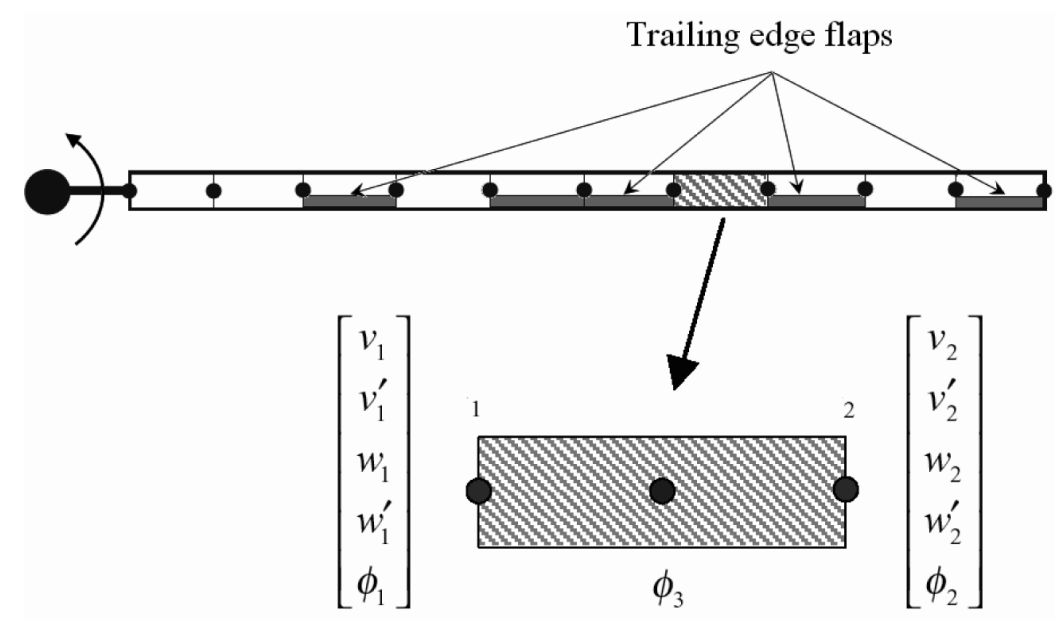

Fig. 1. Finite elements for composite rotor blade with trailing edge flap.

trailing edge flap configuration and investigated the influence of flap system design parameters such as actuator signal amplitude, frequency and phase on the system response. This paper presents a four-bladed articulated composite rotor with independently controlled three plain active flaps on each blade.

\section{Analytical model}

The baseline rotor analysis is adapted from UMARC [27]. The blade is assumed to be an elastic beam undergoing flap bending, lag bending, and torsional deformations. Hamilton's principle states that the integral over some time of the potential and kinetic energies and the external virtual work is zero. The coupled blade/trailing-edge flap periodic equations of motion based on Hamilton's variational principle generalized for a non-conservative system is defined as:

$$
\delta \Pi=\int_{0}^{2 \pi}(\delta U-\delta T-\delta W) \delta \psi=0
$$

where $\delta \mathrm{U}$ is the virtual variation of the elastic strain energy, $\delta \mathrm{T}$ is the virtual variation of the kinetic energy, and $\delta \mathrm{W}$ is the virtual work done by external forces. The detailed derivation of $\delta \mathrm{U}, \delta \mathrm{T}$, and $\delta \mathrm{W}$ for rotor blades can be found in [28].

The following briefly outlines the analysis and solution procedure. The analysis incorporates finite element methodology in space and time. The rotor blades are discretized into a finite number of beam elements as shown in Fig. 1, each with 11 degree of freedom which correspond to variations in flap and lag bending deflections, and elastic torsion. The periodic equations of motion are solved using the finite element in time method with six equally sized time elements. Continuity of slope and displacement between the elements is enforced by Lagrangian shape functions for flap and lag bending deflections and continuity of displacements for elastic twist is enforced by Hermite shape functions [29].

A quasi-steady aerodynamic model is implemented for rotor blades with a free wake model for rotor inflow. A compressible unsteady trailing edge flap aerodynamic model developed by Leishman and Hariharan [30] is implemented in this study. A coupled propulsive trim procedure is carried out to solve for the blade steady response in modal space via finite element method in time. The force summation method is applied to calculate blade root loads in the rotating frame and the hub loads in the fixed frame.

In order to have multiple independently moving flaps along the blade, the spatial elements may be modeled with a trailing edge flap. The trailing-edge flap motion is prescribed, and as such, actuator dynamics are neglected for this study [31]. However, trailing-edge flap aerodynamic and inertial effects are included in $\delta \mathrm{W}$ as additional virtual work. It is assumed that stiffness changes due to the existence of the plain flaps are negligible. A quasi-steady model 


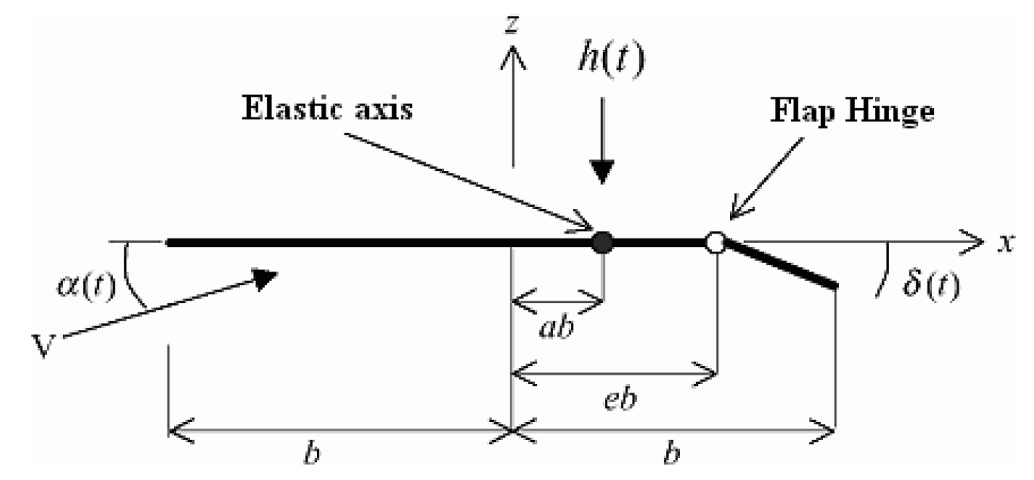

Fig. 2. Nomenclature for a thin airfoil rotor blade with trailing edge flap.
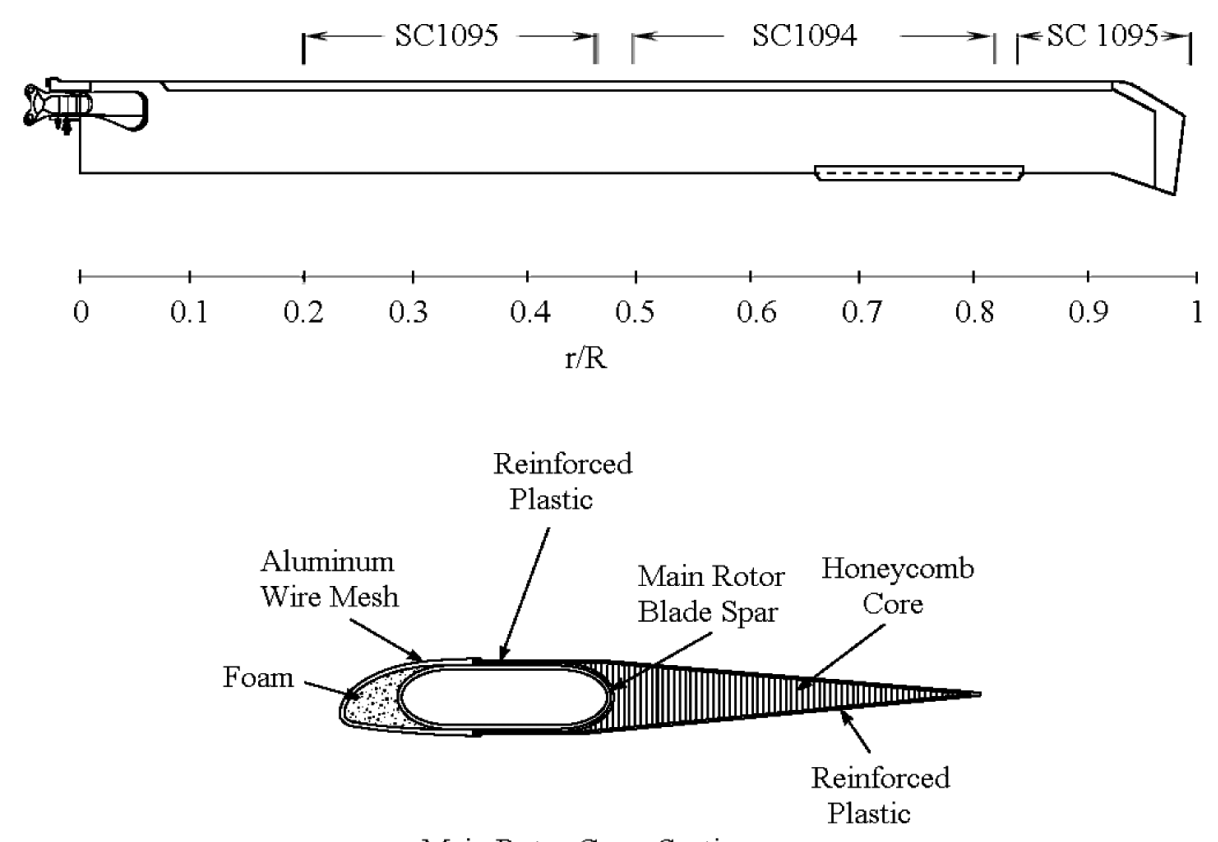

Main Rotor Cross-Section

Fig. 3. Geometry and cross-section of composite rotor blade.

adapted from Theodorsen's theory [32] is used to model the aerodynamically balanced flap shown in Fig. 2. This model considers the gap sealed, that is, no leakage of fluid between the flap and the base airfoil.

The coupled blade/trailing-edge flap equations of motion that are solved using finite elements in space and time are nonlinear and periodic. Because the actuation force driving the flap is assumed to be periodic, the trailing-edge-flap response will also be periodic. Therefore, periodic boundary conditions are applied to the temporal elements.

Assembling the blade finite element equations and applying boundary conditions results in Eq. (1) becoming

$$
M \ddot{q}+C \dot{q}+K q=F
$$

where $M, C, K$ and $F$ are the blade global mass, damping, stiffness matrices and load vector, respectively, and $q$ is the blade global displacement vector which is defined as,

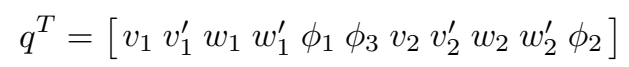

where $v, v^{\prime}, w$ and $w^{\prime}$ are the displacement and slope for lagwise and flapwise bending degrees of freedom at each node, respectively, and $\phi$ is the twist for the torsion degree of freedom at each node, as shown in Fig. 1. 
Table 1

Summary of baseline rotor blade structural parameters for analytic model

\begin{tabular}{ll}
\hline Number of blades $N_{b}$ & 4 \\
Rotor radius $R, \mathrm{ft}$ & 26.83 \\
Blade chord $c, \mathrm{ft}$ & 1.7405 \\
Blade mass/length $m_{0}, \mathrm{slug} / \mathrm{ft}$ & 0.2785 \\
Rotational Speed $\Omega$, rad/sec & 27.018 \\
Precone $\beta_{p}$, deg & 0 \\
Blade linear twist $\theta_{0}$, deg & -8 \\
Flapwise and lagwise mass moment of inertia $k_{m 1}, k_{m 2}$ & $0.182,0.926$ \\
Blade Profile & $\mathrm{SC} 1095, \mathrm{SC} 1094$ \\
\hline
\end{tabular}

Table 2

Calculated natural frequencies for $\mathrm{UH}-60$ rotor and results in literature

\begin{tabular}{lccccc}
\hline & \multicolumn{5}{c}{ Frequency (/rev) } \\
\cline { 2 - 6 } Mode ID & Calculated & Floros [34] & Theodore [35] & Ruzicka [36] & Bao [37] \\
\hline Lag 1 & 0.276 & 0.276 & 0.268 & 0.27 & 0.271 \\
Flap 1 & 1.030 & 1.036 & 1.035 & 1.03 & 1.036 \\
Flap 2 & 2.640 & 2.633 & 2.819 & 2.63 & 2.747 \\
Lag 2 & 3.008 & 3.112 & 5.180 & 4.09 & - \\
Torsion 1 & 2.889 & 3.535 & - & 4.86 & 4.229 \\
Flap 3 & 4.623 & 4.706 & 4.652 & - & 4.516 \\
Lag 3 & 9.549 & 7.746 & 7.889 & - & - \\
Torsion 2 & 10.700 & 10.273 & - & 14.59 & - \\
\hline
\end{tabular}

Table 3

Trailing edge flap properties

\begin{tabular}{lc}
\hline Inner (1st) Flap Location & $0.4 R \sim 0.6 R$ \\
Middle (2nd) Flap Location & $0.7 R \sim 0.8 R$ \\
Outer (3rd) Flap Location & $0.9 R \sim 1.0 R$ \\
Flap chord ratio, $c_{f} / c$ & 0.2 \\
\hline
\end{tabular}

\section{Results and discussion}

For the numerical study, a fully-articulated four-bladed rotor similar to the UH-60 rotor is considered. The detailed design data used in the present study were based on [33] and manufacturer's data. The properties of the baseline helicopter rotor blade shown in Fig. 3 are summarized in Table 1. The elastic stiffnesses are expressed in non-dimensional form.

Before results for trailing edge flap control are presented, the baseline rotor blade analysis is evaluated by comparing the calculated blade natural frequencies and the coupled mode shapes with the results in literature. Table 2 compares calculated rotating natural frequencies of the UH-60 rotor between the present analysis and previous results in literature. A good agreement between the results is observed. The small discrepancy may be a result of different structural properties used in the analyses.

Mode shapes for the first three flap, first three lag and first two torsion modes are shown in Figs 4-6.

The effect of single trailing-edge flap on the vibration level of both fully elastic and rigid blade rotor models have been investigated and it is shown that the predicted vibration level using the rigid blade model is much less than that of using the elastic blade model [38]. Making the rotor blade very stiff is a simple solution but this will result in high bending stresses and moments. Trailing edge flap mechanism generates additional flapwise bending moment to dynamically straighten the blade. It is possible to reduce both the rotor blade hub loads and vibrations by straightening the fully elastic rotor blade using the additional loads obtained from the multiple active trailing edge flaps.

Based on this approach, three partial span plain type trailing edge flaps are used to straighten the blade. The properties of the trailing edge flaps are summarized in Table 3. The three mode shapes corresponding to the calculated lowest blade natural frequencies for flap mode are investigated to decide on the most effective trailing edge flap location. One flap is located at the outboard region of the blade, $0.9 R \sim 1.0 R$, one is located around the mid-span region, $0.4 R \sim 0.6 R$, and the other one is located between the inner and the outer flaps, as shown in Fig. 7. 

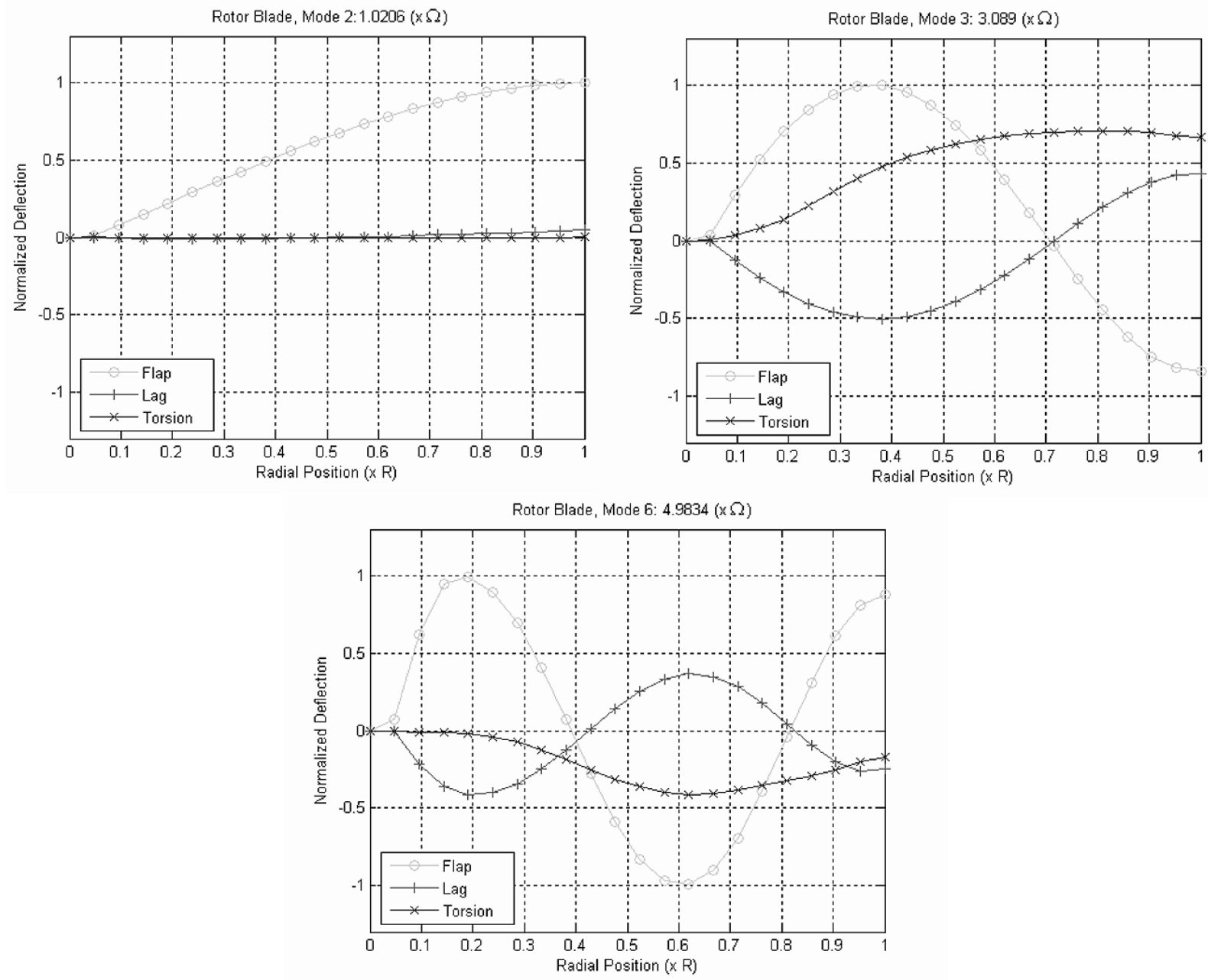

Fig. 4. Rotor blade coupled flap mode shapes.

The flap span is $10 \%$ of rotor blade length for both of the outer flaps while it is $20 \%$ of rotor blade length for the inner flap. The additional flapwise bending moment generated by the inner flap is low compared to the outer flaps due to geometric location of the inner flap and low aerodynamic pressure. Therefore, span for inner flap is decided to be wider than the other two flaps.

\subsection{Flap controller}

There are several parameters that should be considered to analyze effect of multiple trailing edge flaps on the system response. Number, location, geometry and length of flaps are critical parameters as well as actuator signal output properties such as frequency, amplitude and phase of the flap motion.

In the present investigation, the basic angle profile for the flaps is as follows:

$$
\alpha_{i}(t)=A_{i} \sin \left(2 \pi f_{i} t+\phi F_{i}\right)
$$

where $\alpha_{i}$ is the flap angle, $A_{i}$ is the amplitude, $f_{i}$ is the frequency and $\phi F_{i}$ is the phase angle of actuating signal for the $\mathrm{i}^{\text {th }}$ flap. Open loop control is applied on the flaps and inputs of varying actuator signal amplitude, frequency and phase are used to identify their effects on the multiple trailing edge flap system response.

For the purpose of comparison of individual flap angle control parameters on the system response, the vibration index $V B I$ is defined as: 

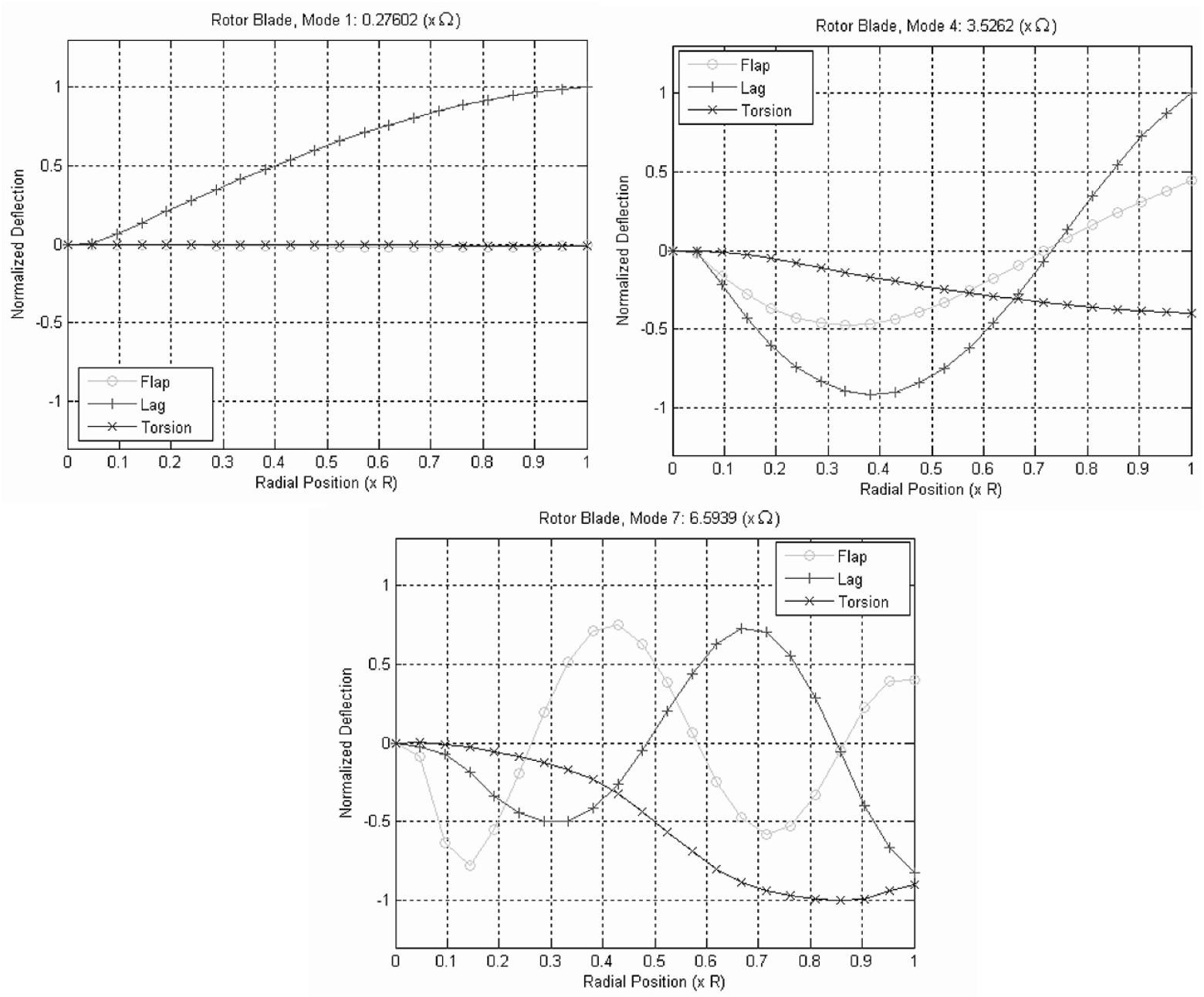

Fig. 5. Rotor blade coupled lag mode shapes.
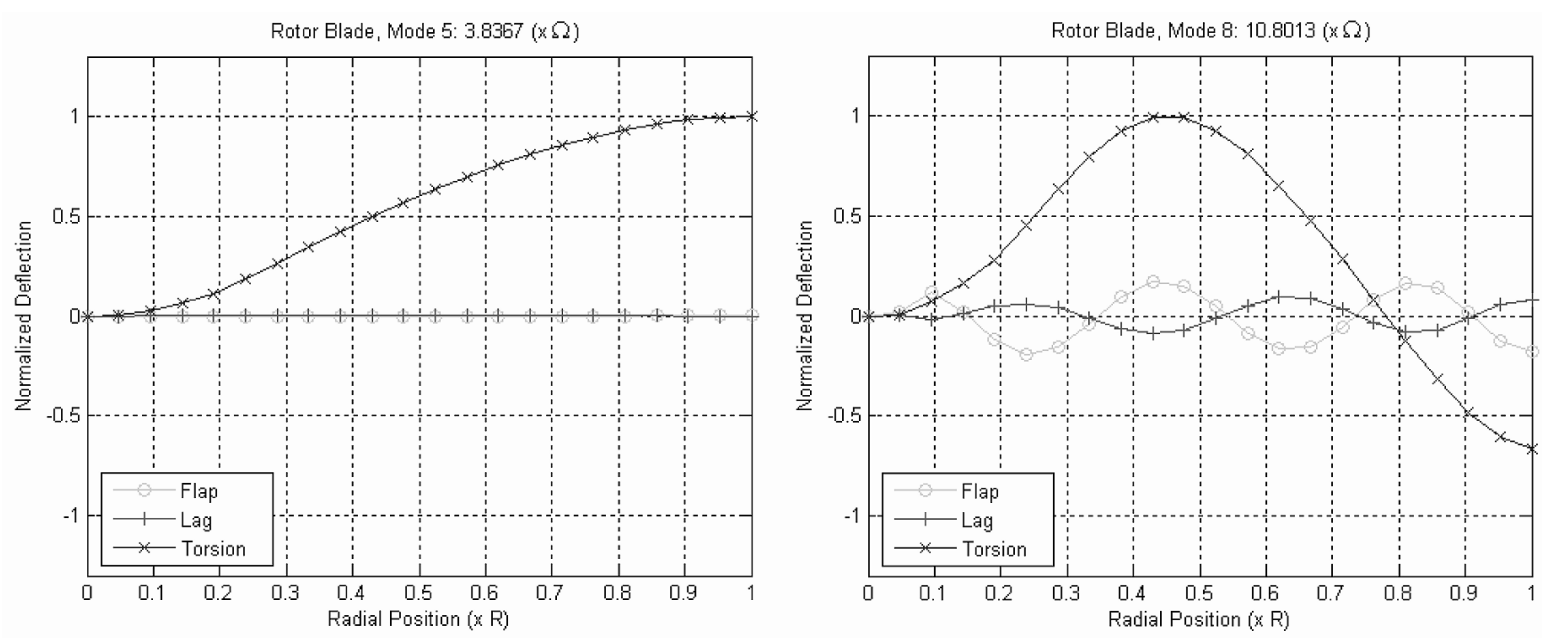

Fig. 6. Rotor blade coupled torsion mode shapes. 


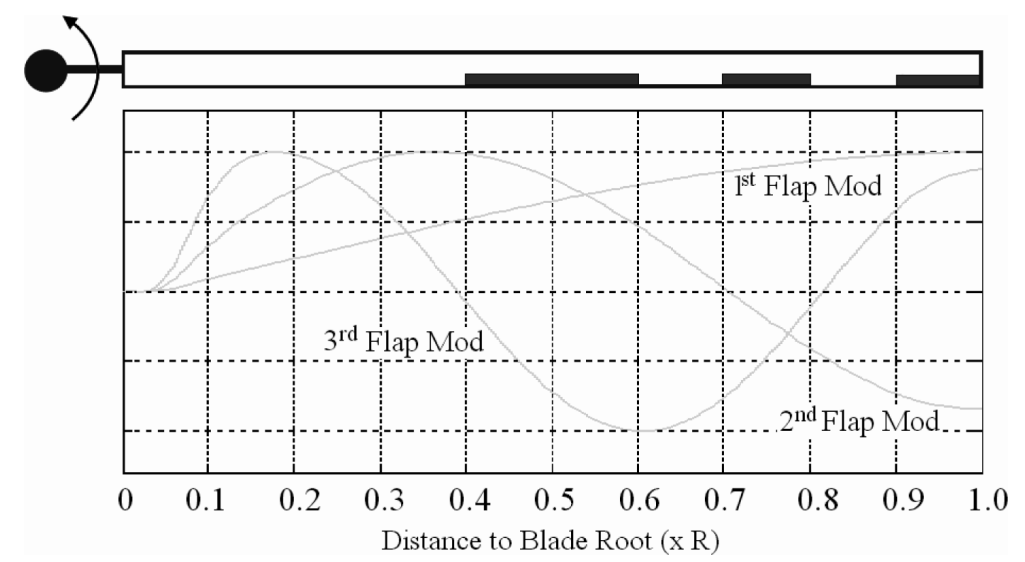

Fig. 7. Triple trailing edge flap location.

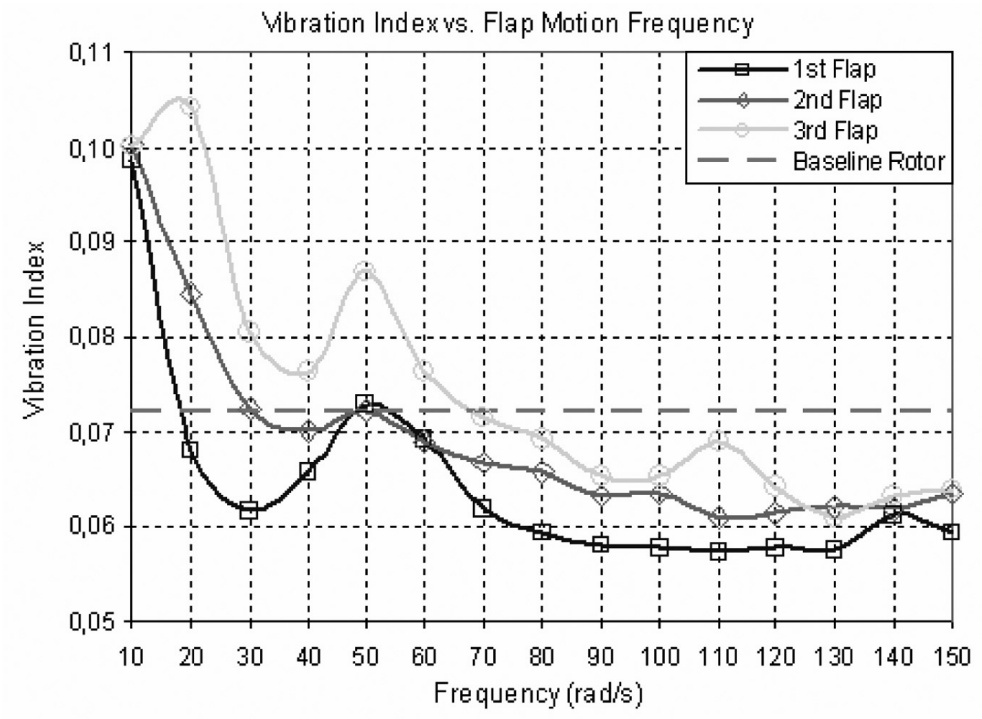

Fig. 8. Effect of flap motion frequency on vibration index.

$$
V B I=\sqrt{F_{y}^{2}+F_{z}^{2}+M_{y}^{2}+M_{z}^{2}}
$$

where $F_{y}$ and $F_{z}$ are vibratory hub flapwise and lagwise shear forces, and $M_{y}$ and $M_{z}$ are vibratory hub flapwise and lagwise bending moments. The axial hub load, $F_{x}$ and axial hub moment, $M_{x}$ are relatively very small compared to the flapwise and lagwise loads and therefore they are not included in the $V B I$. All the forces and moments are nondimensional quantities.

\subsection{Effect of flap controller signal frequency}

Trailing edge flaps are actuated at different input frequencies to analyze effect of input signal frequency on the system response. A maximum flap input limit of \pm 4 degrees is imposed and nominal phase angles are set to be $0^{\circ}$ for the inner (first) flap, $90^{\circ}$ for the middle (second) flap and $180^{\circ}$ for the outer (third) flap. The aim in this phase angle setting of flaps is to deflect the inner flap to opposite direction of the outer flap in order to reduce the flapwise bending moment. Hover conditions are considered.

Before applying the open loop flap control inputs, the vibration index for the baseline rotor blade is calculated. The effect of flap control input frequency on the system response is investigated first. For this purpose, flap control 


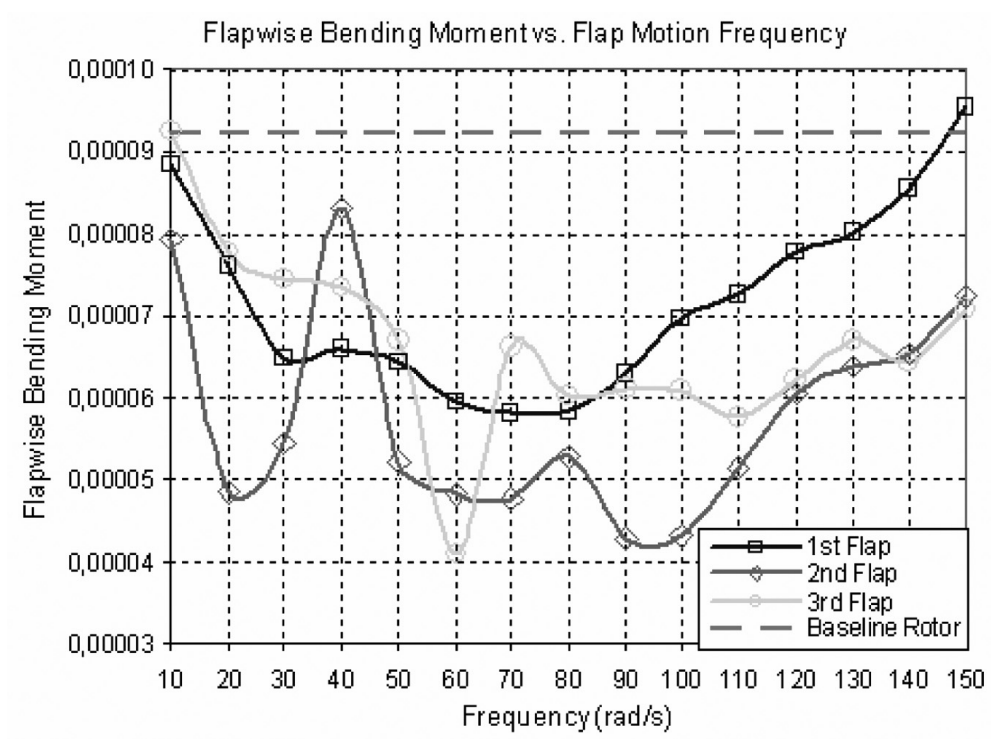

Fig. 9. Effect of flap motion frequency on flapwise bending moment.

Lagwise Bending Moment vs. Flap Motion Frequency

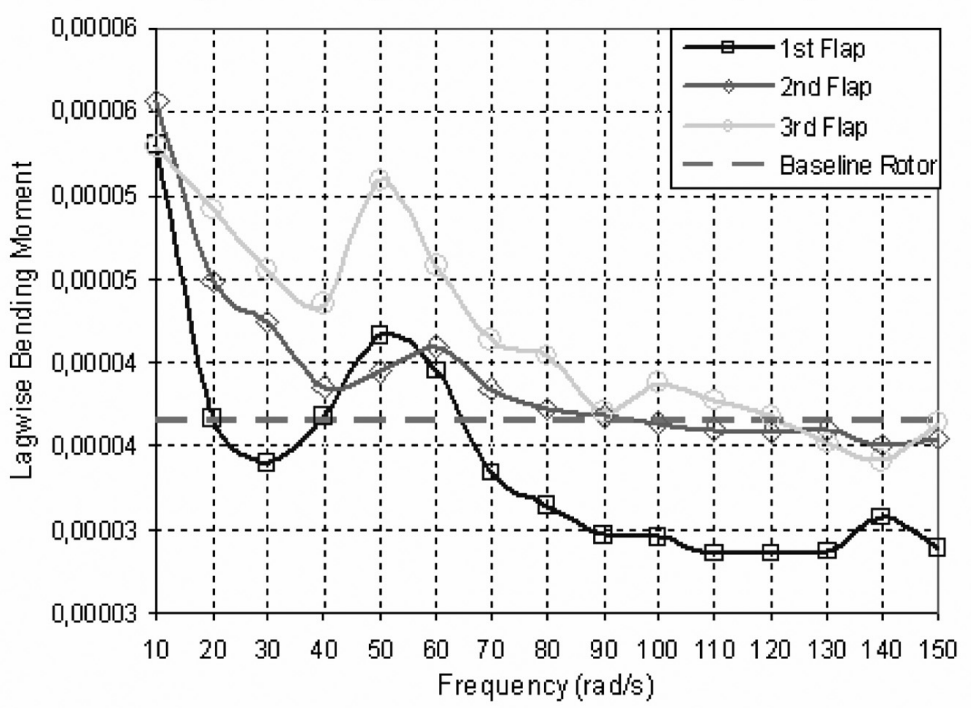

Fig. 10. Effect of flap motion frequency on lagwise bending moment.

input angle and phase are kept constant and one flap at a time is actuated at a frequency from 10 to $150 \mathrm{rad} / \mathrm{s}$ and the results of effect of flap motion frequency on vibration index, flapwise and lagwise bending moments and shear forces are plotted in Figs 8-12. The hub forces and moments are nondimensionalized with respect to $m_{0} \Omega^{2} R^{2}$, and $m_{0} \Omega^{2} R^{3}$, respectively.

The results show that, for each of the flaps there is decrease in vibration index as flap actuator frequency increases. For any of the three flaps, the vibration index becomes lower than the vibration index of baseline rotor blade at frequencies $70 \mathrm{rad} / \mathrm{s}$ and above. The calculations indicate that there is $21 \%, \% 16$ and $15 \%$ reductions in vibration index of the first, second and third flaps, respectively compared to the baseline rotor vibration index.

The reduction of considered flapwise bending moment, $M_{y}$ is $37 \%, 69 \%$ and $56 \%$ for the first, second and third flaps, respectively. However there is significant increase in the flapwise shear force $F_{y}$. At frequencies $60 \mathrm{rad} / \mathrm{s}$ and 


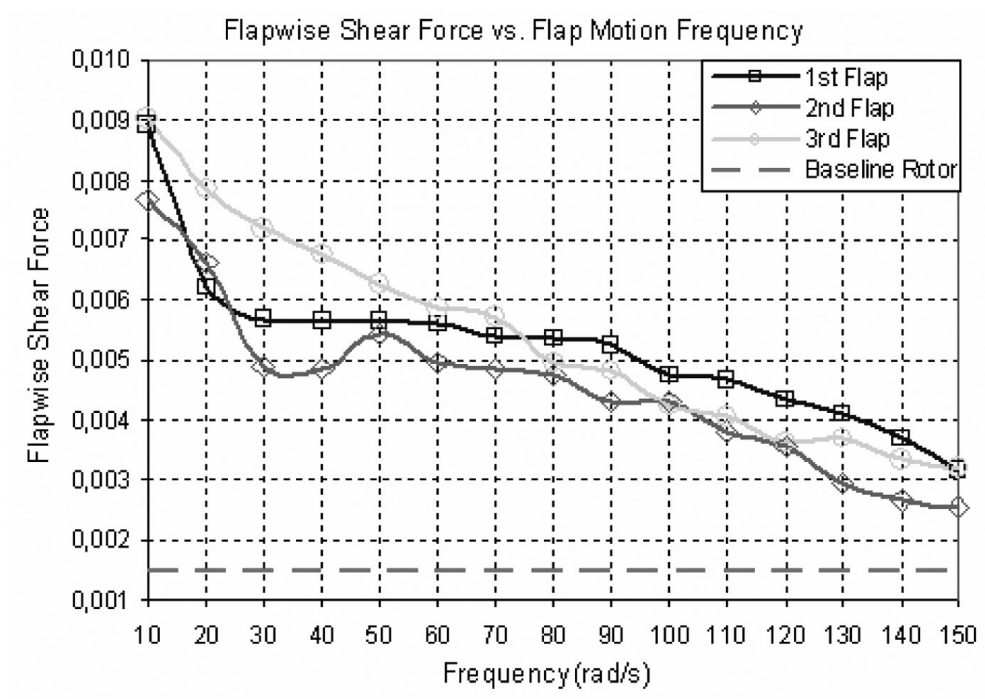

Fig. 11. Effect of flap motion frequency on flapwise shear force.

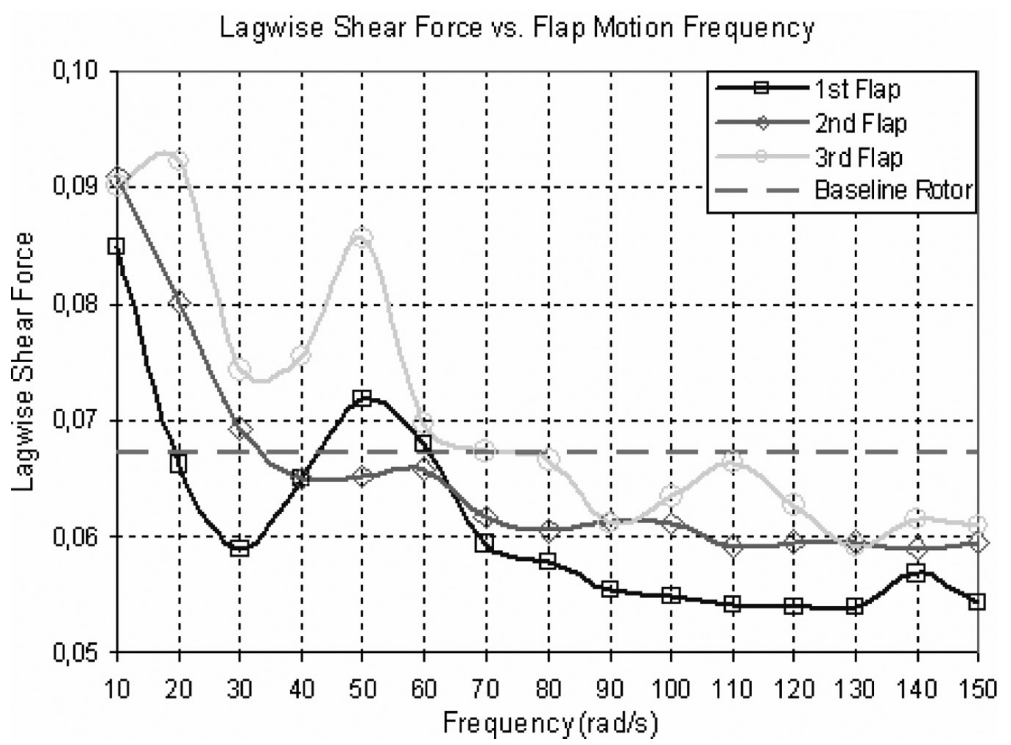

Fig. 12. Effect of flap motion frequency on lagwise shear force.

above, lagwise shear force, $F_{z}$ becomes lower than the baseline blade. Similarly, at frequencies $60 \mathrm{rad} / \mathrm{s}$ and above, lagwise bending moment $M_{z}$ decreases and becomes lower than the baseline blade at frequencies above $120 \mathrm{rad} / \mathrm{sec}$.

Based on the results obtained, it is concluded that the flaps are to be actuated at third, fourth or upper harmonics of blade's first flapping natural frequency $(28.73 \mathrm{rad} / \mathrm{s})$. Besides, frequency inputs are not to be the same for each flap.

\subsection{Effect of flap controller signal amplitude}

Although previous results show that the trailing edge flap system would certainly include an active control system generating inputs at multiple rotor harmonics, it is of interest to examine the open loop response at single frequency as a function of the amplitude and phase of the flap motion. This provides a general understanding of the influence 


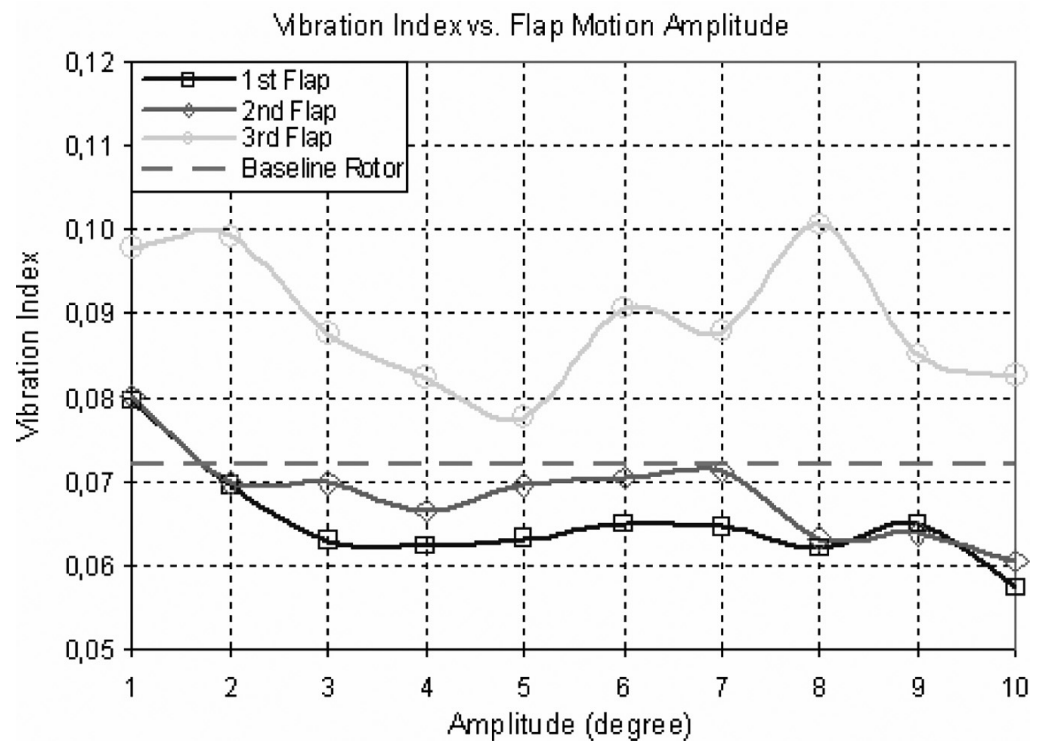

Fig. 13. Effect of flap motion amplitude on vibration index.

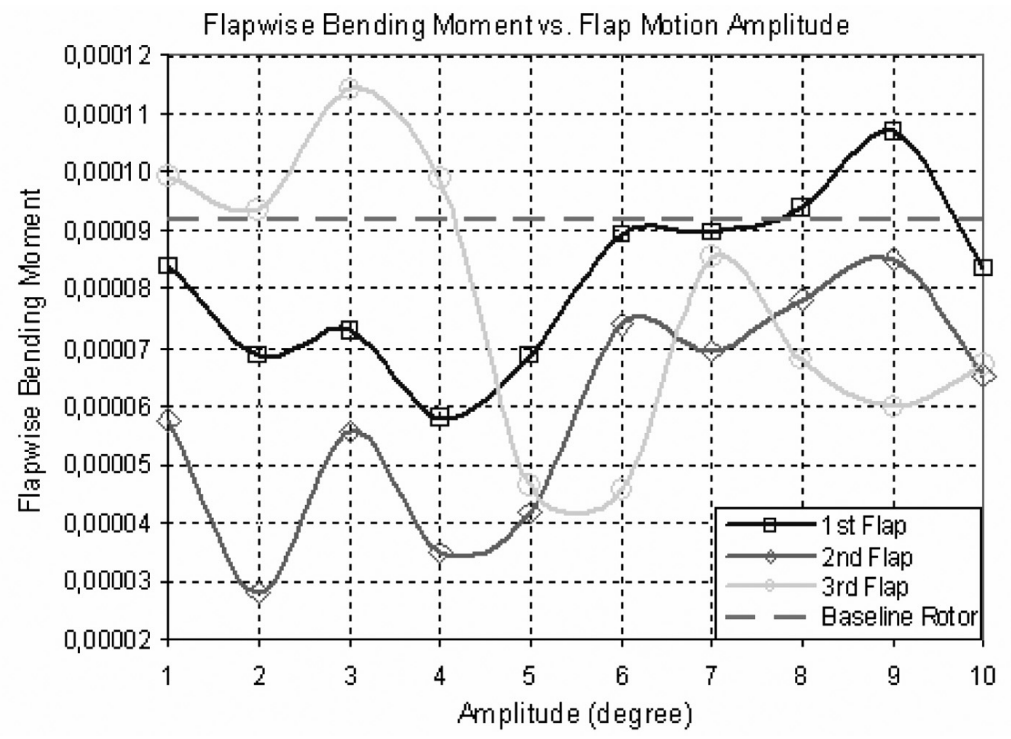

Fig. 14. Effect of flap motion amplitude on flapwise bending moment.

of the flap actuator properties on the various components of the fixed system vibratory loads. For this purpose, flap motion frequency is chosen as $75 \mathrm{rad} / \mathrm{s}$ and phase of actuation are set as $0^{\circ}, 90^{\circ}$ and $180^{\circ}$ for the first, second, and third flaps, respectively. Keeping frequency and phase angle constant, only one flap is actuated at each time, at amplitudes ranging from $1^{\circ}-10^{\circ}$ and the results are plotted in Figs $13-17$.

It is observed that vibration index becomes lower than the vibration index of baseline rotor blade for the inner flaps and up to $20 \%$ reductions in vibration index can be obtained at flap angles of $3^{\circ} \sim 5^{\circ}$. For the outer flap, minimum vibration index is obtained at $5^{\circ}$ flap angle but this value is $7 \%$ above the baseline rotor vibration index. At flap angles $4^{\circ} \sim 8^{\circ}$, the flapwise bending moment, $M_{y}$ becomes lower than baseline value for all three flaps and reductions up to $60 \%$ can be obtained. However, the flapwise shear force, $F_{y}$ become greater than the baseline values.

The calculated lagwise bending moment and shear force values become lower than the baseline values if only the 


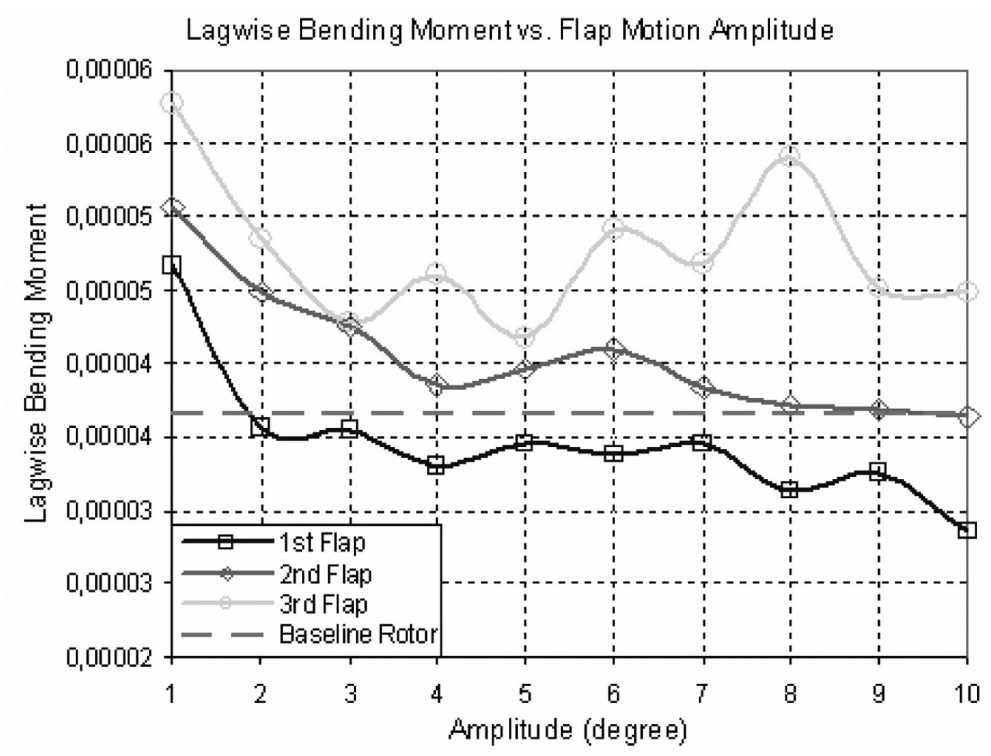

Fig. 15. Effect of flap motion amplitude on lagwise bending moment.

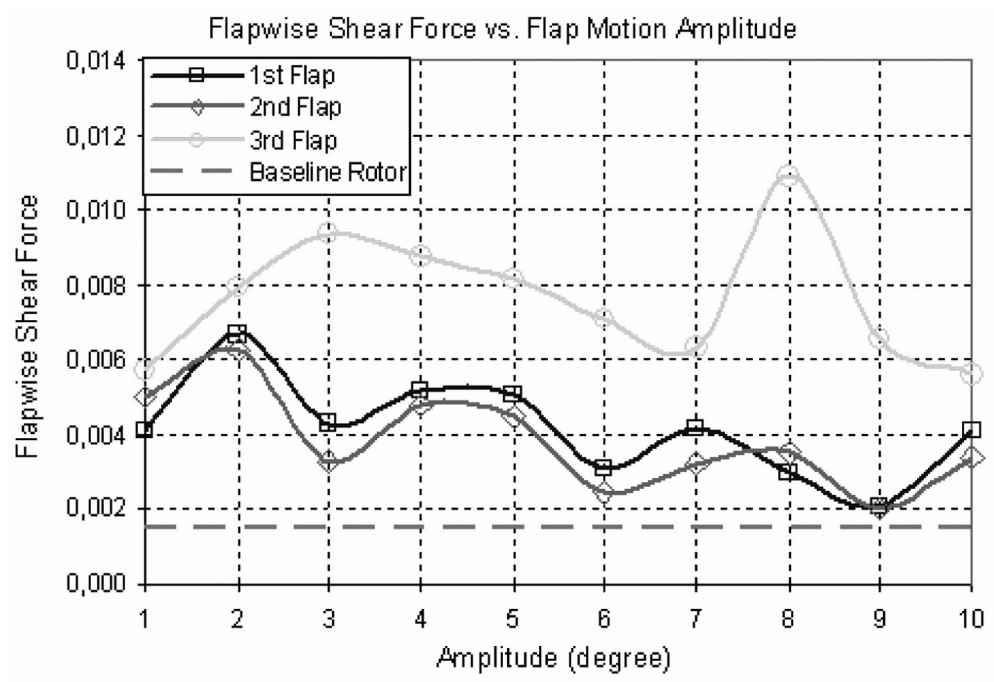

Fig. 16. Effect of flap motion amplitude on flapwise shear force.

inner flap is actuated and becomes greater if only the outer flap is actuated. When only the second flap is activated, the lagwise shear force becomes less than baseline values while lagwise bending moment becomes greater than baseline value. Changing the flap angle amplitude only does not always provide reduction in the vibration index and this shows that the flap angle signal parameters are to be considered together and that a suitable combination of these parameters are to be selected.

\subsection{Effect of flap controller signal phase angle}

The effect of flap motion phase angle on the system response is analyzed. Flap control input signal frequency is set to $75 \mathrm{rad} / \mathrm{s}$ and a maximum flap input limit of \pm 4 degrees is imposed to examine the system response as a 


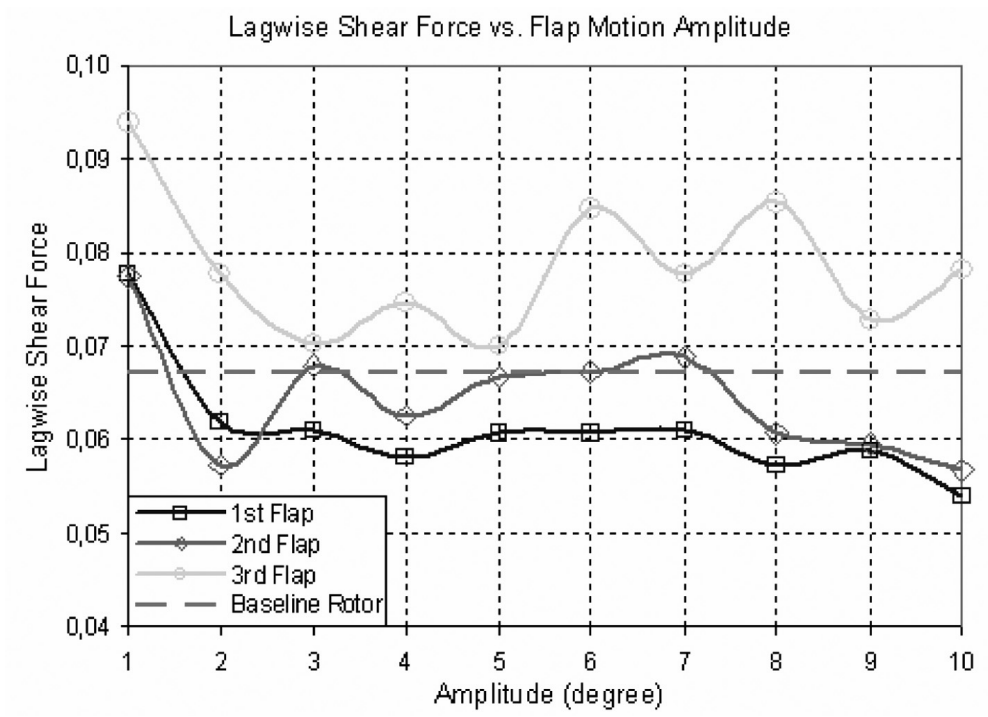

Fig. 17. Effect of flap motion amplitude on lagwise shear force.

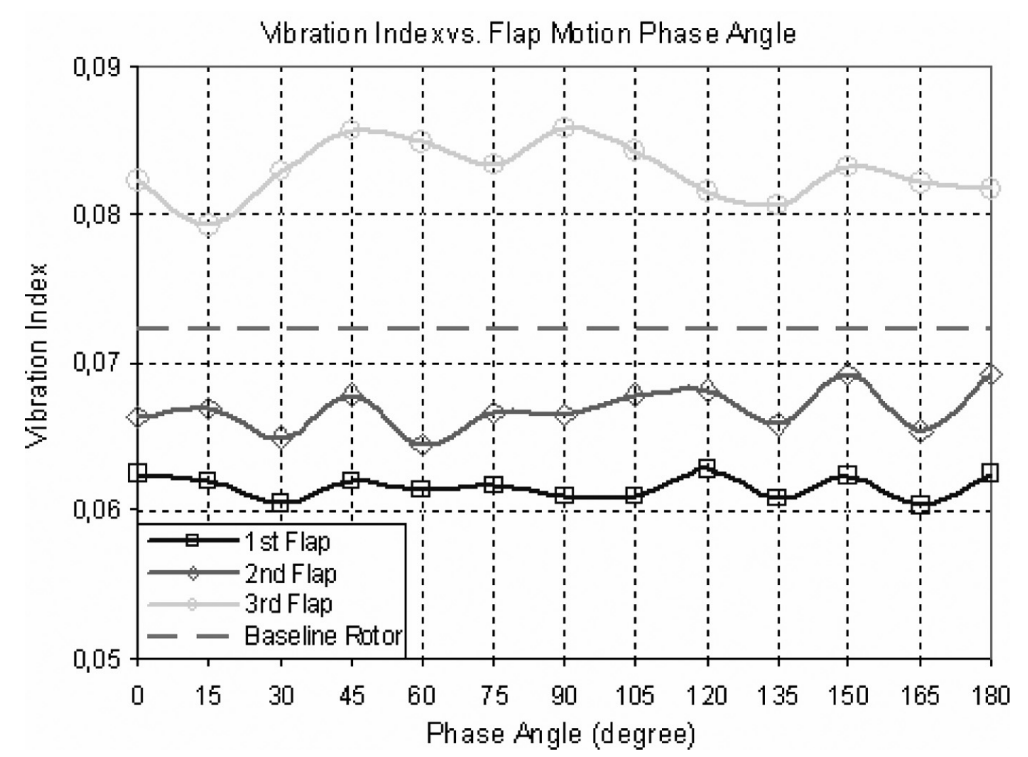

Fig. 18. Effect of flap motion phase angle on vibration index.

function of phase angle of the flap motion. Only one flap is actuated at each time, at phase angles ranging from $0^{\circ}-180^{\circ}$. The results are plotted in Figs $18-22$.

It is observed that small reductions up to $20 \%$ in the vibration index can be obtained by changes in phase angle of flap motion. Flap angle signal parameters are to be handled together and a suitable combination of these parameters are to be selected. Based on the results, it is phase angles of for the first, second and third flaps are determined as $165^{\circ}, 60^{\circ}$ and $15^{\circ}$ to minimize the vibration index.

\subsection{Simultaneous control of multiple flaps}

The results above show that all three flaps should be actuated at different frequency, amplitude and phase angle combinations so as to minimize the vibration index and blade root loads. In order to minimize the number of 


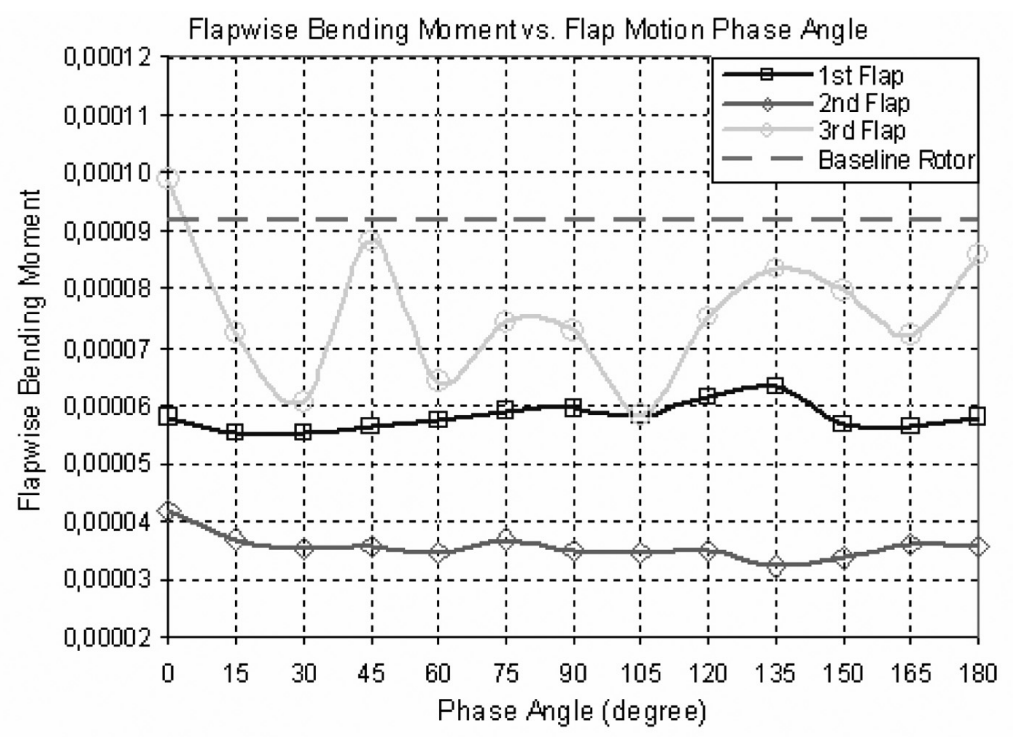

Fig. 19. Effect of flap motion phase angle on flapwise bending moment.

Lagwise Bending Moment vs. Flap Motion Phase Angle

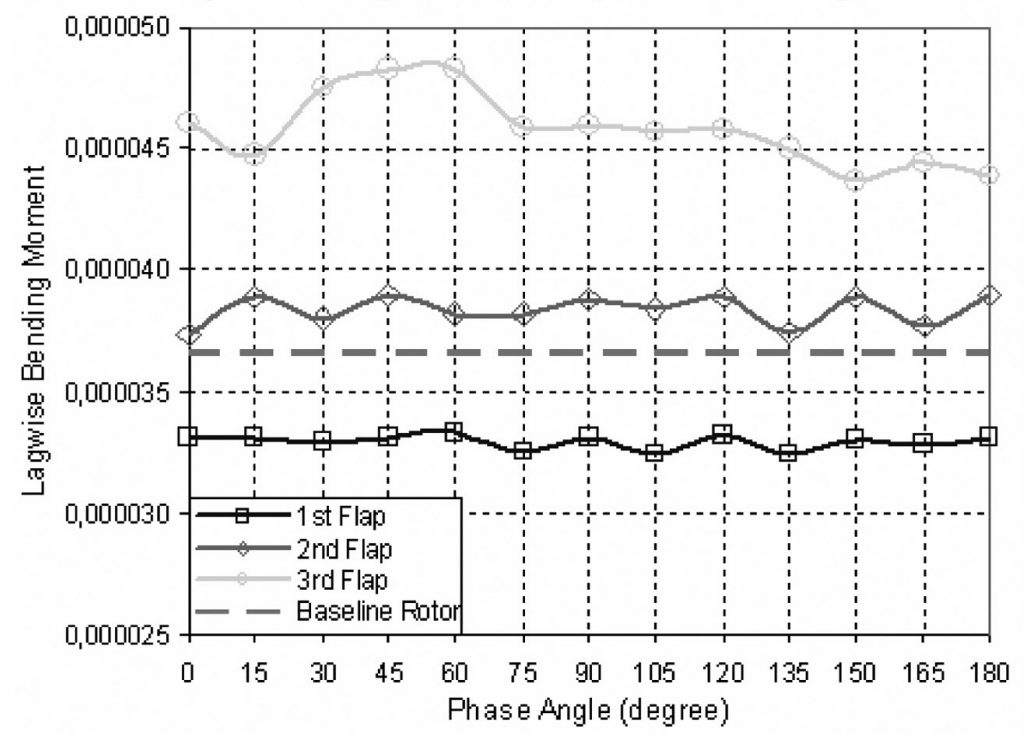

Fig. 20. Effect of flap motion phase angle on lagwise bending moment.

parameters, some decisions are made and some parameters are set based on the results above for simultaneous control of multiple flaps. First, it is decided that the flap angle amplitudes are the same, restricted to $\pm 5^{\circ}$ each. Based on the results, the phase angles of the first, second and third flaps are determined as $165^{\circ}, 60^{\circ}$ and $15^{\circ}$. The motion profile for the triple flap configuration is determined as shown in Fig. 23.

Results obtained from single frequency input studies shows that the flaps are to be driven at third, fourth or upper harmonics of blade's first flapping natural frequency $(28.73 \mathrm{rad} / \mathrm{s})$. Therefore, the analysis is focused on controlling the flaps at multiple frequencies between 70-140 rad/s simultaneously. All the three flaps are actuated simultaneously, but during each case the frequency of only one flap is changed from 70 to $140 \mathrm{rad} / \mathrm{s} \mathrm{with} 5 \mathrm{rad} / \mathrm{s}$ intervals while the other two flaps are actuated at a fixed frequency of $75 \mathrm{rad} / \mathrm{s}$. The vibration index of rotor blade 


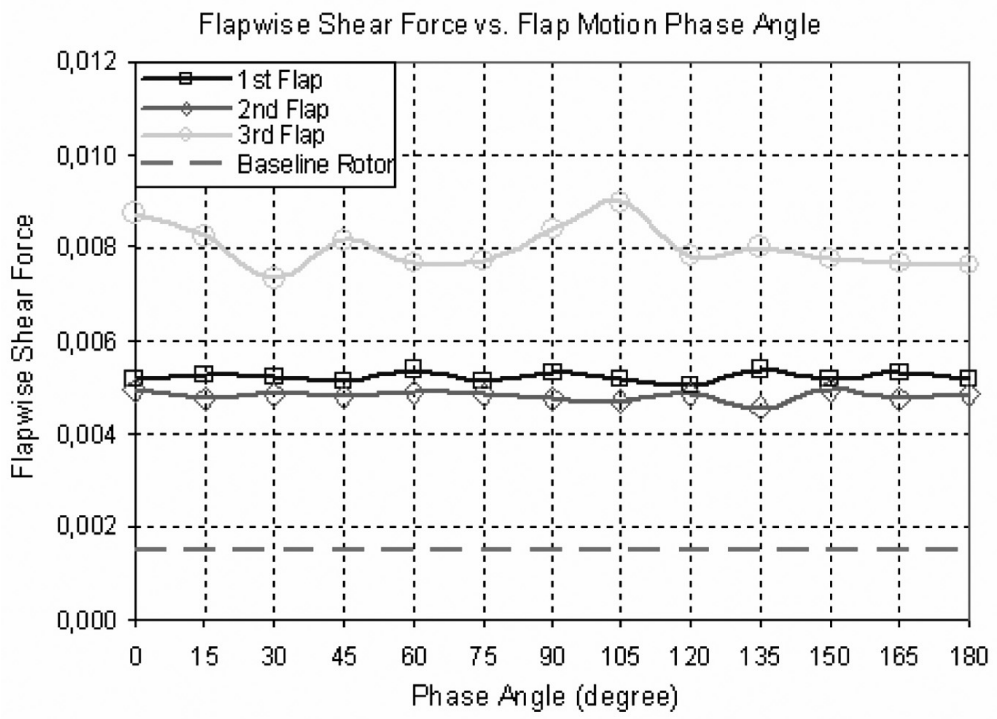

Fig. 21. Effect of flap motion phase angle on flapwise shear force.

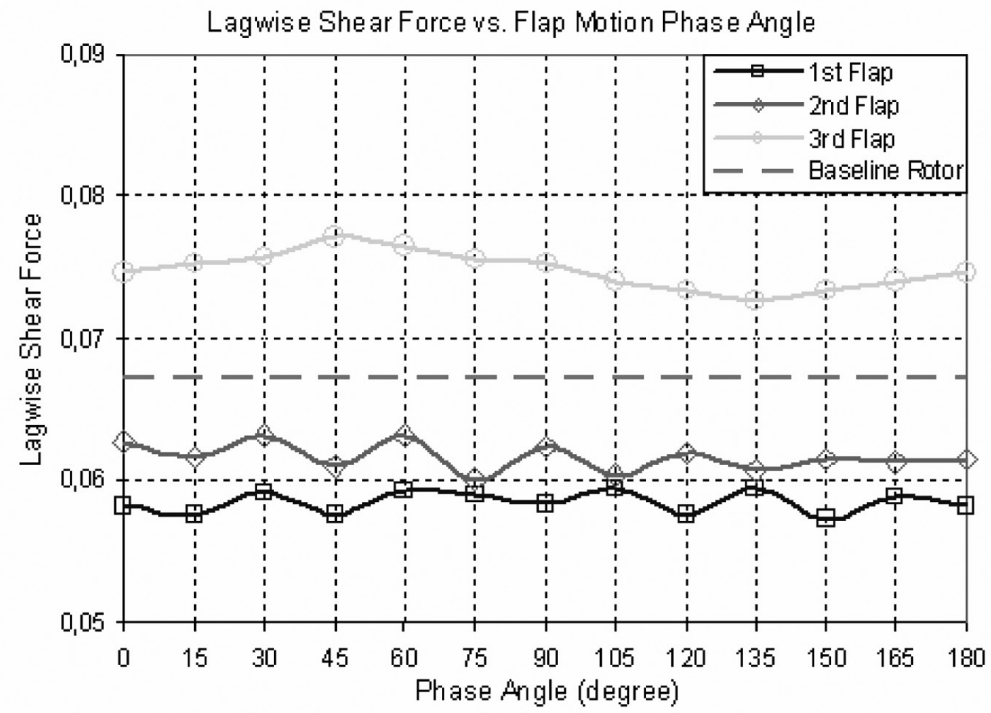

Fig. 22. Effect of flap motion phase angle on lagwise shear force.

as a function of flap input frequency is shown in Fig. 24.

The results show that simultaneous control of flaps at multiple frequencies results in $36 \%$ decrease in vibration index while it was maximum $(21 \%)$ for the single flap control strategy. It is seen that simultaneously activated trailing edge flaps provide better results in reducing the blade root loads and vibrations. The results, i.e., the frequency, amplitude, and phase angle combinations obtained for the flaps by open loop simultaneous control of flaps can be taken as baseline settings for active control of flaps. 


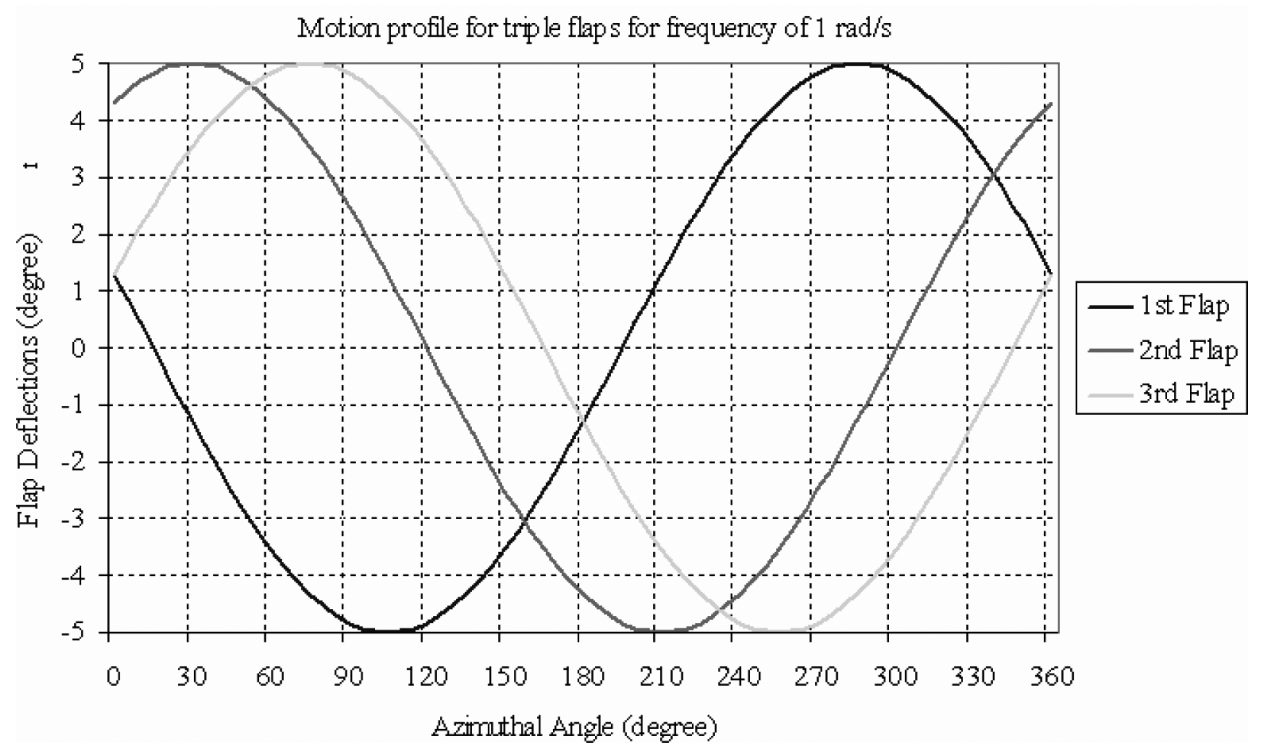

Fig. 23. Motion profile for simultaneously activated triple flaps.

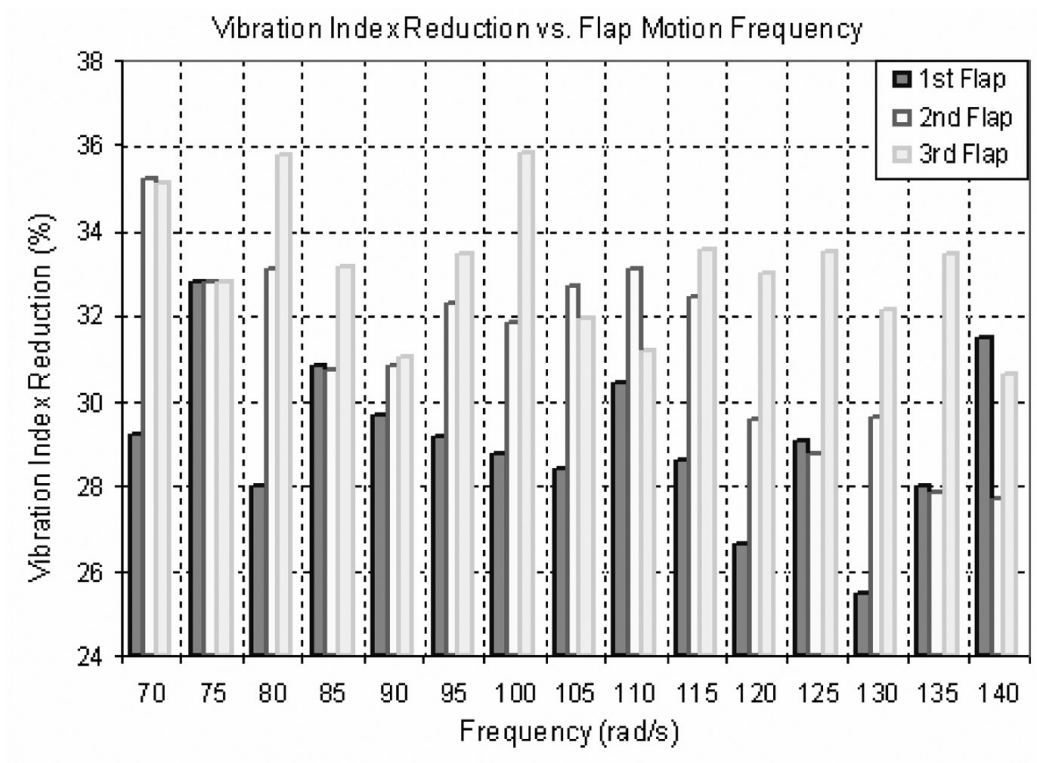

Fig. 24. Effect of flap frequency on vibration index for simultaneous control of triple flaps.

\section{Conclusions}

Multiple active trailing edge flaps are controlled by using open loop controllers to identify the effects of the flap motion profile, i.e., frequency, amplitude and phase of the flap motion on the rotor blade root loads and vibrations. Using a comprehensive model for rotor blade with active trailing edge flaps, natural frequencies and mode shapes of a complex composite helicopter rotor blade is calculated and it is shown that these calculations were in good agreement with the previous results in literature which provided the validation of the baseline rotor blade model and developed computer program. Open loop controllers have been used to control the motion of the trailing-edge flaps and inputs of varying amplitude, frequency and phase are applied on flaps to identify the rotor blade system response. Based on the results, some design criteria are determined for the design of flap controller that will provide 


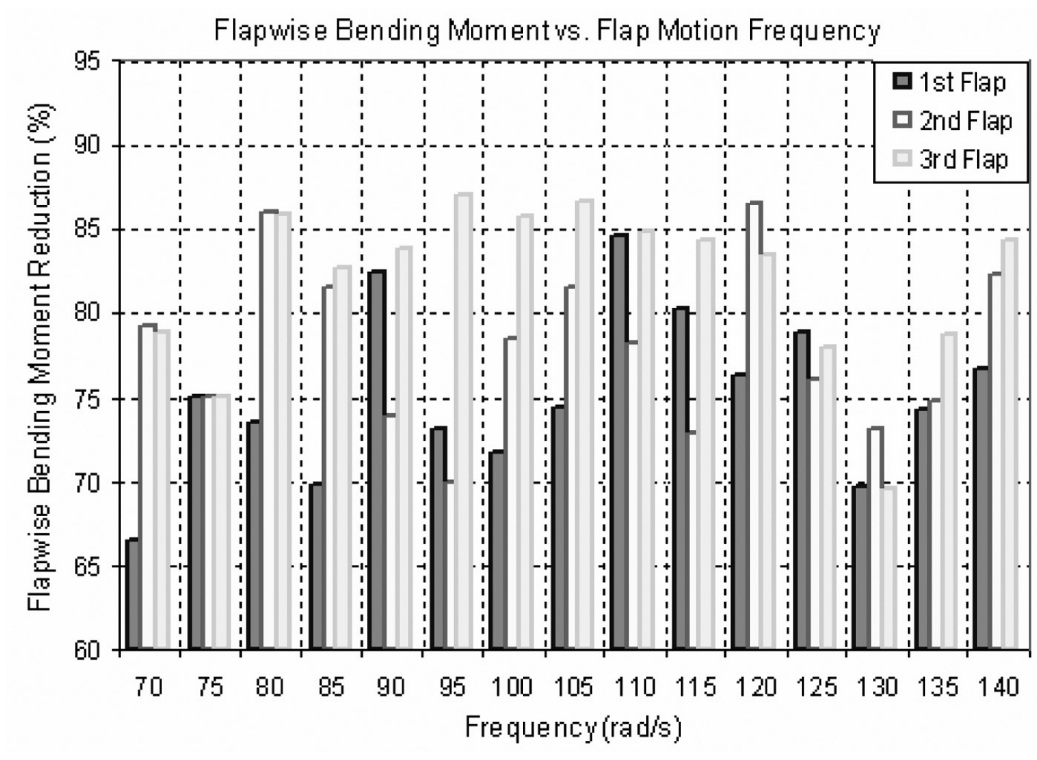

Fig. 25. Effect of flap frequency on flapwise moment for simultaneous control of triple flaps.

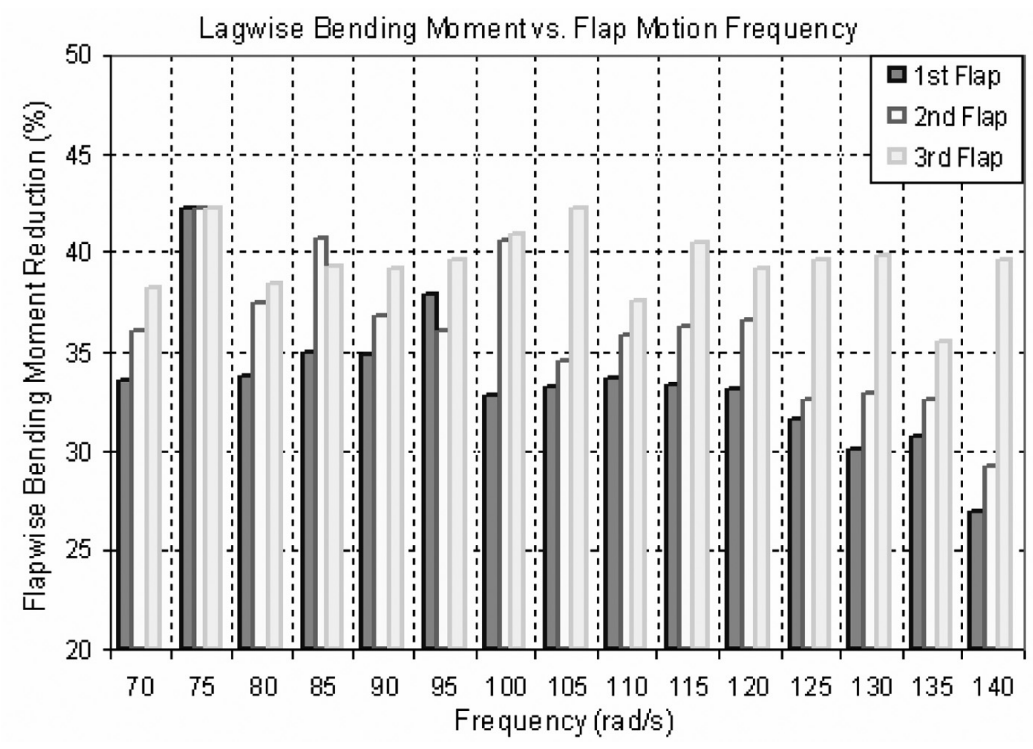

Fig. 26. Effect of flap frequency on lagwise moment for simultaneous control of triple flaps.

flap motion to minimize the rotor blade root loads. It has been demonstrated that implementation of the trailing edge flaps both single and multiple flap configuration is an effective means for reducing the rotor blade loads and vibrations. It is demonstrated that through straightening the rotor blade with multiple trailing edge flap, both the bending moments and vibratory hub loads can be significantly reduced by $36 \%$.

These results indicate that multiple flap configuration is superior over the single flap configuration for hub loads reduction. It is observed that proper selection of flap motion frequencies and phase angles depending on the location of multiple flaps together with imposition of flap deflection limits play an important role in the ability of the active flap, in both configurations, to achieve alleviation of vibrations. It is recommended that future research continue to examine the closed loop control of multiple trailing edge flap system. The results of this study can be used as initial settings of active multiple trailing edge flap motion profile in further closed loop control studies. 


\section{References}

[1] R. Ganguli, Optimum design of a helicopter rotor for low vibration using aeroelastic analysis and response surface methods, Journal of Sound and Vibration 258(2) (2002), 327-344.

[2] F. Nitzsche, D.G. Zimcik, V.K. Wickramasinghe and C. Yong, Control laws for an active tunable vibration absorber designed for rotor blade damping augmentation, Proceedings of the 28th European Rotorcraft Forum, September 2002.

[3] U.T. Arnold, D. Fuerst, T. Neuheuser and R. Bartels, Development of an Integrated Electrical Swashplateless Primary and Individual Blade Control System, American Helicopter Society 63rd Annual Forum, Virginia Beach, USA, May 2007.

[4] F. Gandhi and M.K. Sekula, Helicopter Vibration Reduction using Fixed-System Auxiliary Moments, Proceedings of the American Helicopter Society 58th Annual Forum, Montreal, Canada, June 2002.

[5] V. Giurgiutiu and C.A. Rogers, Review Of Smart-Materials Actuation Solutions For Aeroelastic And Vibration Control, Proceedings of the International Forum on Aeroelasticity and Structural Dynamics, Williamsburg VA, June 1999.

[6] Y. Delrieux, A.L. Pape, P. Leconte, P. Crozier, B. Gimonet and H.M. des Rochettes, Wind-Tunnel Assessment of the Concept of Active Flaps on a Helicopter Rotor Model, Proceedings of the American Helicopter Society 63rd Annual Forum, Virginia Beach, USA, May 2007.

[7] D. Roth, B. Enenkl and O. Dieterich, Active Rotor Control by Flaps for Vibration Reduction - Full Scale Demonstrator and First Flight Test Results, 32nd European Rotorcraft Forum, Maastricht, the Netherlands, September 2006.

[8] K. Noboru, S. Saito, T. Fukami and T. Komura, Design and Performance Evaluation of Full Scale On-board Active Flap System, American Helicopter Society 63rd Annual Forum, Virginia Beach, Virginia, USA, May 2007.

[9] T. Millott and P. Friedmann, Vibration Reduction in Helicopter Rotors Using an Actively Controlled Partial Span Trailing Edge Flap Located on the Blades, NASA TR CR 4611, June 1994.

[10] A.Z. Lemnios and R. Jones, The Servo Flap - An Advanced Rotor Control System, Proceedings of AHS and NASA Ames Research Center Vertical Lift Aircraft Design Conference, San Francisco CA, January 1990.

[11] F.S. Wei and R. Jones, Correlation and Analysis for SH-2F 101 Rotor, Journal of Aircraft 25(7) (1988), 647-652.

[12] F.S. Wei and F. Gallagher, Servo-Flap Rotor Performance Flight Testing and Data Identification, Proceedings of the 57th Annual Forum of the American Helicopter Society, Washington DC, May 2001.

[13] N.A. Koratkar and I. Chopra, Wind Tunnel Testing of a Mach-Scaled Rotor Model with Trailing-Edge Flaps, Journal of the American Helicopter Society 47(4) (2002), 263-272.

[14] F.K. Straub and B.D. Charles, Aeroelastic Analysis of Rotors with Trailing Edge Flaps Using Comprehensive Codes, Journal of the American Helicopter Society 46(3) (2001), 192-199.

[15] R.A. Ormiston, Aeroelastic Considerations for Rotorcraft Primary Control with On-Blade Elevons, Proceedings of the 57th Annual Forum of the American Helicopter Society, Washington DC, May 2001.

[16] T.F. Myrtle and P.P. Friedmann, Vibration Reduction in Rotorcraft Using Actively Controlled Trailing Edge and Issue Related to Practical Implementation, Proceedings of the 54th Annual Forum of the American Helicopter Society, Alexandria VA, May 1998.

[17] J. Milgram, I. Chopra and F. Straub, Rotors with Trailing Edge Flaps: Analysis and Comparison with Experimental Data, Journal of the American Helicopter Society 43(4) (1998), 319-332.

[18] J. Milgram and I. Chopra, A Parametric Design Study for Actively Controlled Trailing Edge Flaps, Journal of the American Helicopter Society 43(2) (1998), 110-119.

[19] N.A. Koratkar and I. Chopra, Analysis and Testing of a Froude Scaled Rotor with Piezoelectric Bender Actuated Trailing-Edge Flaps, Journal of Intelligent Material Systems and Structures 8(7) (1997), 555-570.

[20] N.A. Koratkar and I. Chopra, Analysis and Testing of a Mach Scaled Helicopter Rotor in Hover with Piezoelectric Bender Actuated Trailing-Edge Flaps, 1998 SPIE Conference on Smart Structures Proceedings, San Diego CA, March 1998.

[21] M.V. Fulton and R.A. Ormiston, Hover Testing of a Small-Scale Rotor with On-Blade Elevons, Journal of the American Helicopter Society 46(2) (2001), 96-106.

[22] J. Shen and I. Chopra, Actuation Requirements for a Swashplateless Helicopter Control System With Trailing-Edge Flaps, Proceeding of the 43rd AIAA/ASME/ASCE/AHS Structures, Structural Dynamics, Materials Conference and 10th AIAA/ASME/AHS adaptive structures conference, number AIAA-2002-1444, Denver, Colorado, April 2002.

[23] J. Shen and I. Chopra, A Parametric Design Study for a Swashplateless Helicopter Rotor with Trailing-Edge Flaps, Proceedings of the 58th Annual Forum of the American Helicopter Society, Montreal, Canada, June 2002.

[24] J. Shen, M. Yang and I. Chopra, Swashplateless Helicopter Rotor with Trailing-Edge Flaps for Flight and Vibration Control, Journal of Aircraft 43(2) (2006), 346-352.

[25] P. Crozier, P. Leconte, Y. Delrieux, B. Gimonet, A. Le Pape and H.M. des Rochettes, Wind Tunnel Tests of a Helicopter Rotor with Active Flaps, 32nd European Rotorcraft Forum, Maastricht, the Netherlands, September 2006.

[26] H. Mainz, B.G. Van Der Wall, P. Leconte, F. Ternoy and H.M. des Rochettes, ABC Rotor Blades: Design, Manufacturing and Testing, 31st European Rotorcraft Forum, Florence, Italy, September 2005.

[27] G.S. Bir and I. Chopra, University of Maryland Advanced Rotorcraft Code (UMARC) Theory Manual, UM-AERO 92-02, University of Maryland, College Park, Maryland, 52-75 (1992).

[28] U. Dalli, Helicopter Rotor Blade Vibration Reduction Using Active Flaps, Ph.D. Dissertation, Gazi University, Ankara, Turkey, 2007.

[29] I. Chopra and N.T. Sivaneri, Aeroelastic stability of rotor blades using finite element analysis, NASA CR 166389, 1982.

[30] N. Hariharan and J. Leishman, Unsteady Aerodynamics of a Flapped Airfoil In Subsonic Flow by Indicial Concepts, Journal of Aircraft 33(5) (1996), 855-868.

[31] J. Shen and I. Chopra, Aeroelastic Stability of Trailing-Edge Flap Helicopter Rotors, Journal of the American Helicopter Society 48(4) (2003), 236-243. 
[32] T. Theodorsen and I.E. Garrick, Nonstationary Flow About a Wing-Aileron-Tab Combination Including Aerodynamic Balance, NACA Tech. Rept. 736, 1942.

[33] S.R. Turnour, Flight Dynamics Simulation Modeling for Hingeless and Bearingless Rotor Helicopters, Ph.D. Dissertation, University of Maryland, College Park, Maryland, 2003.

[34] M.W. Floros, Elastically Tailored Composite Rotor Blades For Stall Alleviation and Vibration Reduction, Ph.D. Dissertation, Pennsylvania State University, Pennsylvania, 36-63 (2000).

[35] C.R. Theodore, Helicopter Flight Dynamic Simulation With Refined Aerodynamic Modeling, Ph.D. Dissertation, University of Maryland, College Park, Maryland, 184-185, (2000).

[36] G.J. Ruzicka and D.H. Hodges, A Mixed Finite-Element Treatment of Rotor Blade Elongation, Journal of the American Helicopter Society 48(3) (2003), 167-175.

[37] J. Bao, Development of Mach Scale Rotors With Composite Tailored Coupling for Vibration Reduction, Ph.D. Dissertation, University of Maryland, College Park, Maryland, 75-76, (2004).

[38] T. Millott and P. Friedmann, Vibration Reduction in Helicopter Rotors Using an Active Control Surface located on the Blade, Proceedings of 33rd AIAA/ASME/ASCE/AHS/ASC/ Structures, Structural Dynamics and Materials Conference, AIAA-92-2451-CP, Dallas, TX, 1975-1988, (1992). 

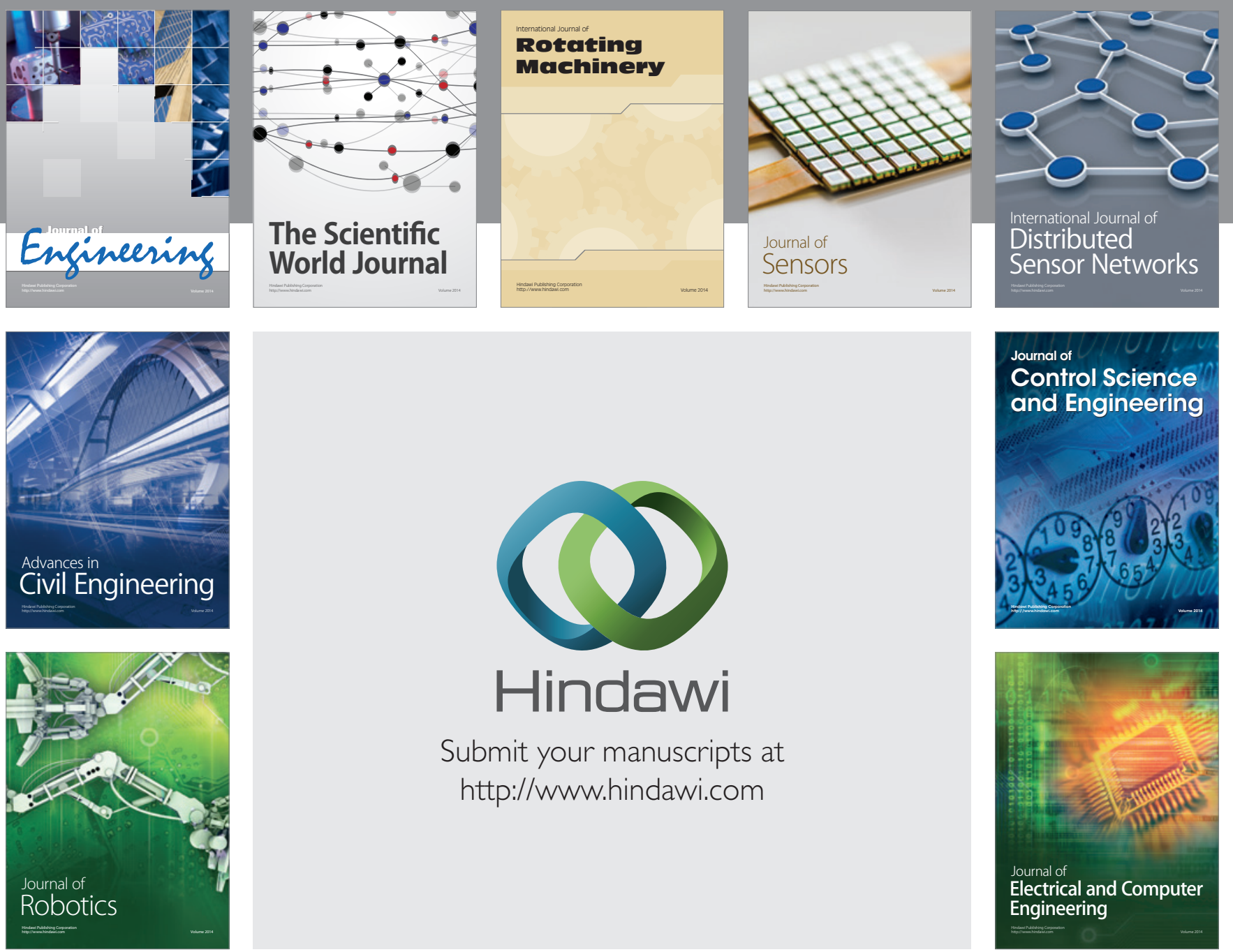

Submit your manuscripts at

http://www.hindawi.com
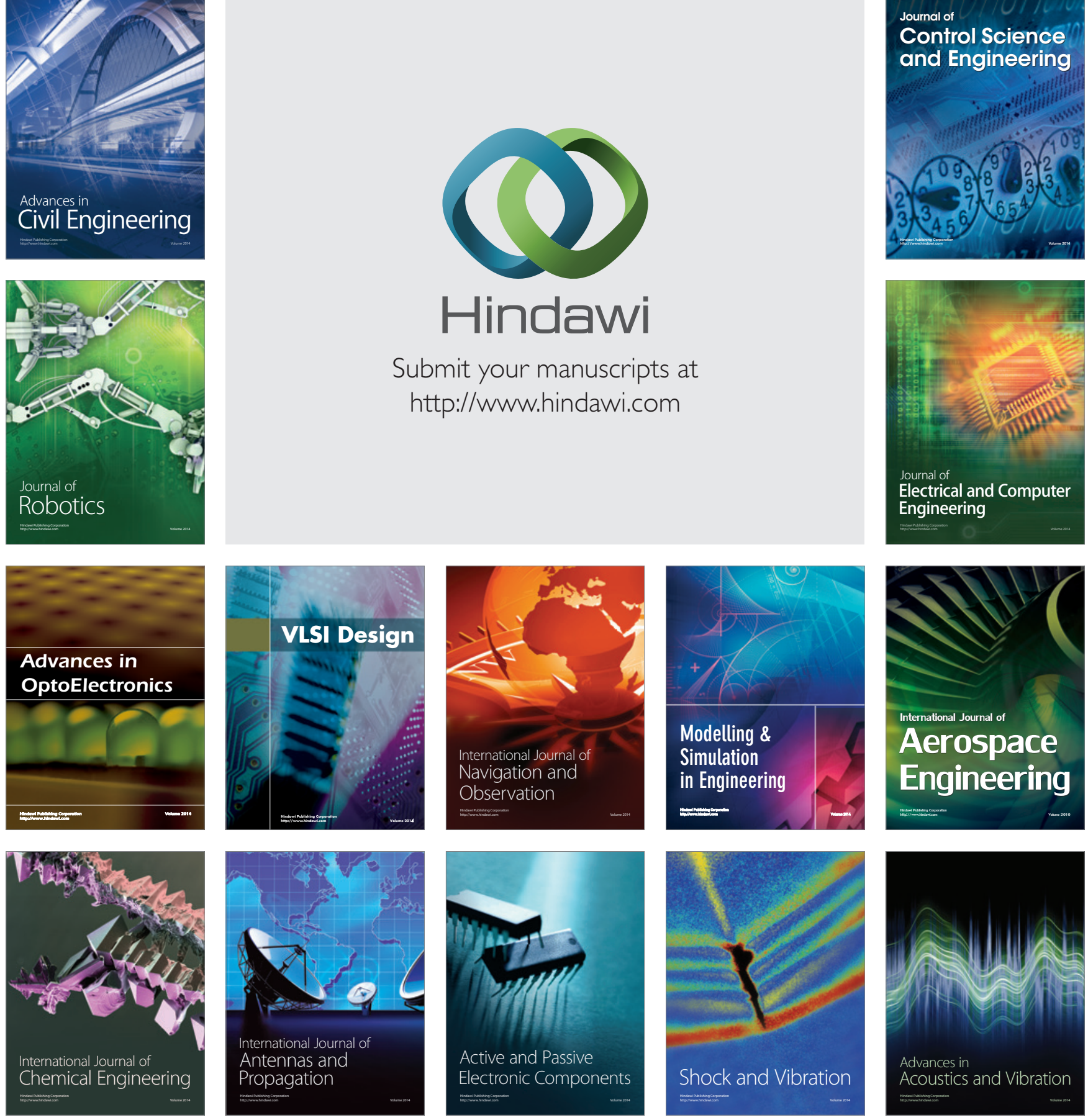